Review Article

\title{
Metasynthesis of Factors Contributing to Children's Communication Development: Influence on Reading and Mathematics
}

\author{
Amber J. Godwin, Mary Margaret Capraro, William H. Rupley, and Robert M. Capraro \\ Texas A\&M University, College Station, TX, USA \\ Correspondence should be addressed to William H. Rupley; w-rupley@tamu.edu
}

Received 14 July 2016; Accepted 21 November 2016; Published 19 February 2017

Academic Editor: Elena Nicoladis

Copyright (C) 2017 Amber J. Godwin et al. This is an open access article distributed under the Creative Commons Attribution License, which permits unrestricted use, distribution, and reproduction in any medium, provided the original work is properly cited.

\begin{abstract}
The purpose of this study is to determine what previous studies have found to be factors that contribute to a child's initial communication development and previously identified effects of reading mathematics storybooks to toddlers or preschoolers. Therefore, it follows that the earlier a preschooler is exposed to mathematics vocabulary, the easier mathematics vocabulary acquisition and understanding can be for that child, which can result in an increase in future academic achievement. This metasynthesis was conducted to gather information on the effects that interactive relationships with caregivers have on a child's ability to communicate and then how symbiotic reading and mathematics interventions can affect a child's ability to think and communicate mathematically. According to the data analyzed for this metasynthesis, caregivers' language relationships help facilitate a child's early communication development and reading and mathematics symbiotic instruction can lead to developing a child's ability to think and communicate mathematically.
\end{abstract}

\section{Introduction}

Reading and mathematics consistently form the foundation of educational curricula in the United States. Still, students in the United States underperform students in other industrialized nations in the areas of reading and mathematics according to the scores on the Programme for International Student Assessment [1, 2]. Meanwhile, recent research from both educational and psychological perspectives has suggested that developmental milestones in reading and mathematics can be symbiotic $[3,4]$. One possible explanation for this connectivity is that students' understanding of mathematics concepts is bound to their mastering of content vocabularies that are used to define, represent, and communicate mathematical concepts [5]. It is feasible that improving children's application of mathematics vocabulary would yield a positive effect on their mathematics achievement.

Mathematics is a language for communication and a tool for discovery $[6,7]$. Learning the vocabulary needed to express oneself effectively is essential for success in today's competitive world economy [8]; this is particularly the case when considering mathematics learning. Mathematics communication takes place every day in some capacity nationwide in middle and high school classrooms where students are expected to know and be able to apply specialized mathematics vocabulary. That is, students must be able to comprehend what mathematics vocabulary means and use those specialized, mathematic concepts when appropriate [9]. However, high school and middle school mathematics coursework is rich in a highly specialized vocabulary that many students are not often exposed to outside of the mathematics classroom. If students are not proficient in utilizing mathematical language to express understanding of mathematics concepts they will be ill-equipped to formulate responses or explain thought processes for problemsolving. Furthermore, students with inadequate mathematics vocabulary knowledge can also find themselves lost in the dense vocabulary introduced as part of mathematics learning. Students who lack mathematics communicative competence can also experience a loss of overall mathematics potential. 
Just as vocabulary development is essential for developing early reading skills, mathematics vocabulary development is key to build a foundation for later mathematics conceptual understanding [5, 10-13] (Samuels \& Flor, 1997). These two vocabularies are interwoven in that the earlier a child can be exposed to mathematical vocabulary words representing concepts, the earlier that child could become proficient in the language of mathematics before formal instruction $[4,14$, 15]. Because children "acquire vocabulary most rapidly and more efficiently through extensive reading" [16, p. 209], one way to nurture the development of mathematics vocabulary in young children is through reading mathematics-themed storybooks.

By reading mathematics-themed storybooks during shared reading time, children can begin to understand and use math vocabulary, even at a young age $[4,7,17]$. Participation at an early age in shared reading encourages behaviors such as mutual questioning, responding, and making stories relevant to the child's life that promotes increased reading engagement [18-20]. So, if children are exposed to and engaged in mathematics storybook readings, then those children would become proficient in the language of mathematics before beginning formalized schooling $[14,15]$.

Hearing mathematics vocabulary associated with represented concepts during a shared storybook reading can lay a foundation for mathematical understanding that promotes a child's future academic achievement in mathematics. Because children must make sense of mathematical vocabulary to communicate and think mathematically [10] (Samuels \& Flor, 1997) introducing math words to young children can start the thought process of mathematical sense-making. Research has shown that, to reach the necessary level of abstract thinking in mathematics, students must begin at the concrete level and gradually move through the representational level [21, 22]. The real experience of hearing stories during shared reading becomes representational when children learn to read and apply mathematics vocabulary later in their classrooms at school.

Dialogue is another important element of vocabulary acquisition (Sénéchal \& Cornell, 1993). It follows then that mathematics dialogue is another dimension of developing a working vocabulary. After all, there exists a codependent relationship between general communication language skills and mathematical language proficiency [23]. That is, in order to gauge a child's understanding of mathematics vocabulary, one must encourage a child to talk about math and then respond in kind creating a reciprocal mathematics dialogue.

One way to achieve a mutual dialogue is to engage in a shared storybook reading. During shared storybook reading, a storybook is read by an "other" (parent, guardian, and teacher) who also facilitates reciprocal conversation with the child as the storybook is being read $[24,25]$. Practicing complementary conversation patterns during shared storybook reading, the child is able to practice good listening skills, good thinking skills, and good speaking skills to communicate about what they understand from the story [18, 26-29]. Through engaging in conversations during shared readings, children are able to build confidence in their ability to process mathematical concepts (such as sorting, charting, and graphing) while nurturing interpersonal relationships [30]. Talking about stories not only helps enhance mathematical understanding but also cultivates relationships by facilitating communication between a child and the facilitating adult "other." Children are also able to use these conversations to help make sense of the world around them [31] through processing and utilizing new vocabulary [25, 32]. Previous studies have highlighted the need for preschool students to engage in constructive dialogue with adult "others" and their peers in order to practice sense-making, a skill that may help specifically with mathematics metacognitive development $[33,34]$. By using mathematics storybooks during a shared interactive reading time, a powerful braiding of advantageous learning experiences can happen with children practicing both computational and reading skills [13] as well as communication and problem-solving skills.

The guided dialogues facilitated by adult "others" reading can help children practice mathematics communication skills that could potentially further their academic achievement in mathematics in later years. Reciprocal conversation with the adult "other" is not the only element of a child's shared storybook experience; sometimes other children are present during shared storybook readings. Having peers present while reading and talking about mathematics storybooks can be advantageous because children can not only participate as active readers but also use dialogue with each other to understand mathematical vocabulary being addressed in the story [7]. By providing children with guidance and practice on how to use language for reasoning and encouraging storybook talks with peers, children can learn to use language more effectively as a tool for solving problems or discussing new concepts or vocabulary $[35,36]$.

Out of participating in interactive dialogues while reading math storybooks, children can get feedback from adult "others," providing a way for children to feel their beliefs or understandings are validated or to correct misconceptions as they occur [37]. However, it is imperative that adult "others" provide feedback in such a way that affords encouragement, understanding, and acceptance for the child to continue participation in the dialogue [38]. If the "other" is consistent in following the pattern of listening to the child's responses to the text and then providing feedback and encouragement, it is more likely that the child will associate positive memories with reading. These positive experiences with reading cultivate a positive attitude toward reading [18, 19, 39-42] and provide children with a "safe" place to learn new things through stories, including mathematics vocabulary.

When children participate in a dialogue with peers they are practicing the skills needed to solve problems and the communication skills needed to work as a team $[6,33-36$, 38,43 ]. These listening, processing, and communication skills will be especially valuable when those children matriculate into middle and high school classrooms and are expected to communicate effectively in groups to solve problems (Mercer, 1995) [36]. Allowing children to use dialogue to "talk out" their understandings during shared readings is another active component of advancing early mathematics 
vocabulary development and fosters efficient inner personal communication [4].

\section{Purpose}

Integrated reading and mathematics instruction has been increasingly encouraged as a means of developing problemsolving, reading, and mathematics skills [44]. Still, actively promoting mathematical communication is a relatively new phenomenon. The purpose of this study is to determine what previous studies have already found to be factors that contribute to a child's initial communication development and previously identified effects of reading mathematics storybooks to toddlers or preschoolers $[7,17]$. The heart of this study is a focus on the communication development that occurs in young children in tandem with the shared experiences of adults with whom they have significant relationships such as parents or caregivers.

Research question one addresses a child's overall communication development with regard to those significant relationships. Investigating communication development as a result of relationships between children and others is the first step in research. These phenomena of interest are whether or not reading and mathematics integration can have an effect on a child's development, which would become irrelevant if one did not first understand how and why the child began communicating initially. In other words, research must first address the process of that communication development to justify extending that pattern of development into both early reading and early mathematics. Therefore, this metasynthesis focuses on these research questions:

(1) What factors contribute to a young child's ability to communicate?

(2) What effect does reading and mathematics integration have on the young child's ability to think and communicate mathematically?

\section{Methodology}

A research-based definition of a metasynthesis is the systematic gathering, synthesizing, and interpreting of previous qualitative research studies [45, 46] (Sandelowski, Barroso, $\&$ Voils, 2007). Some researchers have described the process of metasynthesis as ambiguous and unstructured [47] because metasynthesis is a relatively new way to gather and interpret data from previously existing research. There has yet to be a universally accepted process established for conducting metasynthesis. Thus, researchers urge openmindedness [48] toward those conducting metasynthesis as there is not yet an accepted standard for this form of data analyses. Other perspectives support flexibility within metasynthesis because there are no hard and fast methods for determining the "correct" way to conduct a metasynthesis [47, 48] (Sandelowski \& Barroso, 2003). However, some researchers prefer to have an established methodology in place for conducting metasynthesis: one similar to metaanalysis although the purpose of metasynthesis is to aggregate and interpret previous nonquantitative research findings [46,
48]. The steps of metaanalysis involve the researcher forming a question, distinguishing selection criteria (e.g., particular words, phrases, and methods), and then beginning a hearty search for relevant literature [49] from which effect sizes are obtained. Most researchers adhere to this process when conducting a metasynthesis although the methodology has yet to be solidly defined throughout the academy $[45,46]$ (Sandelowski \& Barroso, 2007).

When conducting a meta-analysis the researcher utilizes distinguishing elements to filter previous quantitative studies while metasynthesis relies on the researcher applying systematic judgment to make such a distinction regarding qualitative and mixed methods studies (Sandelowski \& Barroso, 2003; Sandelowski et al., 2007). One suggested way to consistently determine which articles to include in a metasynthesis is to design an appraisal tool to aid in the filtering of studies $[45,47]$ (Sandelowski \& Barroso, 2003). The purpose of establishing and using an appraisal tool is to maintain consistency and to justify reasons for inclusion and exclusion of studies. The evaluation device should include keywords that were used to conduct the metasynthesis as well as a specific bookend system that specifies the years that were used to refine relevant literature [49]. Using a bookend system can provide reasonable assurance that the researcher has identified the most up-to-date studies of the phenomena while also providing a sensible time period of background as well. Good bookend systems allow the researcher a window with which to look forward and backward into the literature about phenomena in a logical way.

Once the researcher has set a parameter with which to gather data, he or she must identify relevant literature utilizing the developed appraisal tool for the metasynthesis. This appraisal tool is used to sift through relevant literature to include what is essential to the research and to discard studies or other artifacts that may be irrelevant. After using the appraisal tool to filter articles to determine what to include in the metasynthesis, one must begin reading and analyzing relevant literature in order to determine how the remaining studies are related. Previous researchers have advised others to use caution throughout this step of metasynthesis so that the integrity of the context of the literature is maintained [48]. This process of reading and analyzing for thematic congruencies continues until all the literature has been reviewed and common themes have been identified. Once this process has ended, the researcher then carefully examines what previous researchers have already determined in order to expand the overall understanding of a subject or phenomena $[7,48,49]$.

The first step in conducting this metasynthesis involved establishing research parameters including identifying the most appropriate years to bookend relevant literature for this metasynthesis. A special report, School Involvement in Early Childhood, was released by the US Department of Education (Hinkle, 2000), paving the way for substantial changes in the way that early childhood education was viewed. This report highlighted a sharp increase in children attending fullday kindergarten over the previous decade (Hinkle, 2000). Early childhood curriculums were addressed in the No Child Left Behind (NCLB) Act (2002) to compensate for increasing 
kindergarten enrollment numbers and to justify the augmented need for funding for early childhood programs. NCLB was drafted after the release of this report, later in 2000 with overwhelming support from the US population in response to School Involvement in Early Childhood (Hinkle, 2000) and other similar studies. Because 2000 has been identified as a crucial milestone in US educational policy, research, and practice, in the areas of both reading and early childhood instruction, the scope of this metasynthesis includes literature from 2000 until 2014. Because this study was conducted in the fall of 2015, using that year as a bookend for the study was determined to be the most appropriate bookend year to gather a complete review of related research that had been published by that point.

Relevant literature was identified using EBSCO, JSTOR, and LibCat databases to locate previous research. EBSCO is an information service that is a leading provider of research databases, e-journals, magazine subscriptions, ebooks, and discovery service for the academic, medical, and research communities. JSTOR stands for Journal Storage and is another leading information service provider primarily for researchers in a variety of academic fields. LibCat is an internal search engine at Texas A\&M University that stands for "library catalog."

A leading article that involved the benefits of dialogic reading with children was previously identified in an earlier metasynthesis [50]. This main article was the inspiration for the current metasynthesis because of the many positive benefits of dialogic reading as well as the practical and relevant advice given for how to use dialogic reading with children. Relevant literature for the current metasynthesis was identified based on the search phrases peculiar to that leading article (toddlers, dialogs \{language\}; picture books; language acquisition; reading aloud to others; parent-child relationship; reading motivation; mathematics) using the years 2000-2014. The search resulted in 459 artifacts on EBSCO and 102 artifacts on JSTOR and 18 on LibCat equaling a total of 579 related artifacts. These 579 artifacts included books, journal articles, dissertations, policy papers, reports, conference proceedings, and assorted 19 reference materials including bibliographies and handbooks. A list of all artifacts was printed to compare them to identify any duplicate artifacts. Three duplicates were found in the three lists that included all artifacts. Those duplicates included the guiding article [50] and two others [51, 52]; no other article was repeated; at this point there was 576 total, unique artifacts included at the metasynthesis.

Then an appraisal tool was developed to provide a static justification for inclusion in the study. This appraisal tool was created based on thematic associations with the research questions that this study was attempting to answer. The appraisal tool included refined search key terms to create a more precise method for inclusion or elimination. According to this appraisal tool, each artifact had to contain either the word "toddlers" or the word "preschoolers" and one of the following terms: discourse, language, relationships, development in reading, or development in mathematics to be included in this metasynthesis.
The title and abstract of each artifact were read and coded according to the appraisal tool that provided the filtering criteria. That is, each artifact had to have either the word "toddlers" or the word "preschoolers" and one of the following terms: discourse, language, relationships, development in reading, or development in mathematics. This filtering method created a justification for a coding of "yes," "maybe," or "no" for each artifact. According to these criteria, 19 artifacts were coded "yes" and 18 artifacts were coded "maybe." The artifacts coded "maybe" alluded to the terms found in the appraisal tool but it was unclear if inclusion in the metasynthesis would be appropriate. Some artifacts were coded "no" and then eliminated from the metasynthesis because they centered on another area of study. For example, studies involving deaf education, bilingual education, regionally specific research outside the United States, and research on elementary-aged students were no longer considered for inclusion in this study as their content was outside the parameters of this metasynthesis. At this point, 37 of the original 579 artifacts were coded either "yes" or "maybe" and thus considered for further review.

Complete copies of these 37 "yes" and "maybe" artifacts were obtained for further analysis to verify inclusion in the study with particular attention paid to the 18 artifacts coded "maybe." These 18 article titles and brief abstracts alluded to two of the criteria on the appraisal tool though it was unclear at this point whether or not they would be appropriate for inclusion in the study. After accessing complete copies of the aforementioned "maybe" coded artifacts and reading those in their entirety, a second round of coding and eliminating process began. Some examples of themes in the "maybe" artifacts that were recoded "no" during round two included international studies on using storybooks as instructional tools. Six articles that were coded "maybe" were recoded "yes" as they included three or more of the criteria on the appraisal tool [53-58]. After reviewing all "yes" and "maybe" coded articles, 25 of the original 576 unique artifacts were coded "yes" and included in this metasynthesis. A flow chart illustrating the evaluation and elimination process used in this metasynthesis is found in Figure 1.

Each of the remaining 25 artifacts was reread in its entirety and again appraised individually according to the appraisal tool to ensure that those marked for inclusion were suitable for this study. After this third evaluation of included artifacts, each artifact was summarized in one sentence or less according to thematic resonance found therein. This summary served as a sorting system that provided a medium with which to organize and synthesize artifacts. The majority of the 25 artifacts contained information about communication patterns in children, with only seven of the 25 focusing on how to facilitate the communication development of children.

\section{Findings}

4.1. Factors Contributing to a Child's Ability to Communicate. The most predominant theme found in this metasynthesis 


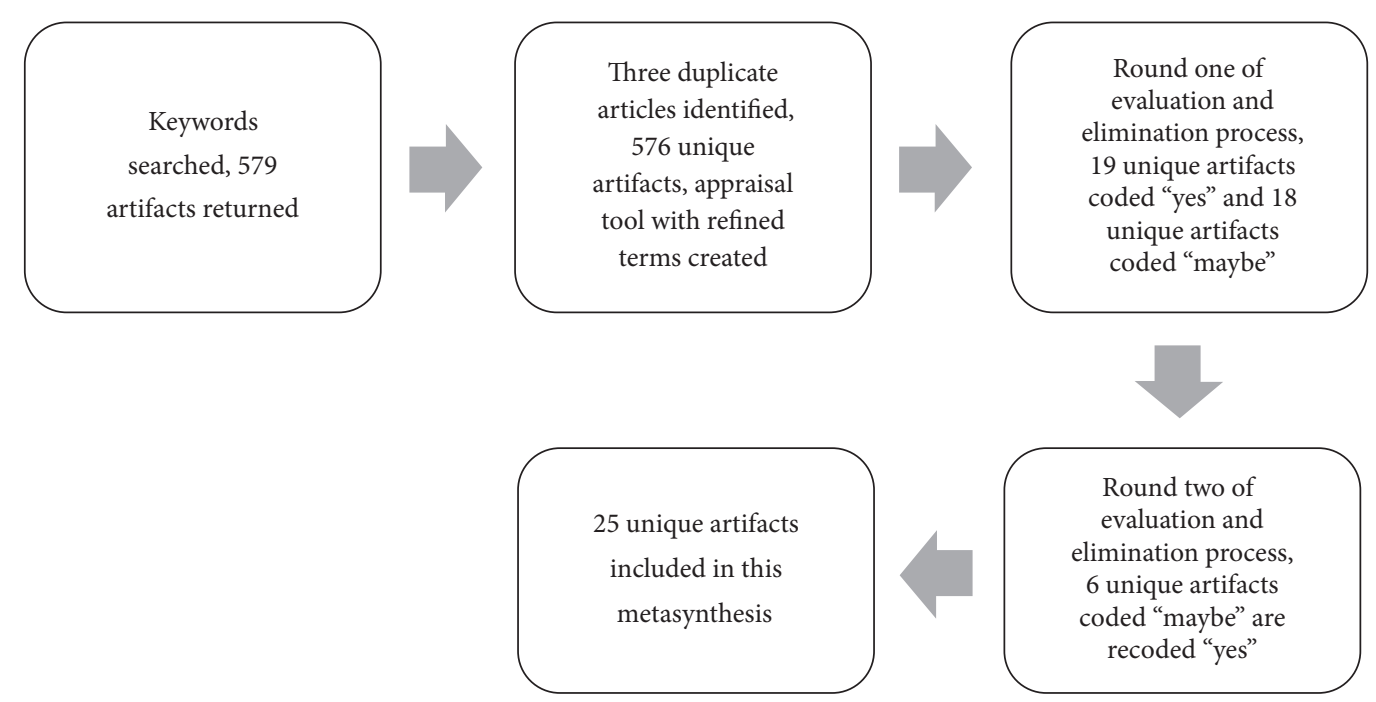

FIGURE 1: Order of evaluation and elimination process.

was that of factors that contribute to early childhood communication development. Most artifacts contained data supporting the claim that communication development occurs as a result of shared social interactions with significant adults such as parents or caregivers. Within that overarching theme, two subcategories were identified: sociocognitive behaviors that develop in infants and children as a result of social interactions and bioecological factors that contribute to linguistic and emergent literacy development of infants and children.

4.1.1. Sociocognitive Behavioral Development. There is an increasing interest in understanding the reasons for and the processes contributing to infant and child sociocognitive development. Sociocognitive behaviors are identified as interdependent and interwoven cognitive behaviors (e.g., thinking, reasoning) that one practices in the context of socializing (e.g., communicating with others, searching for intimacy) [59]. Emerging research claims that infants attempt to "reach out" and express themselves through physical and sometimes behavioral communication methods beginning at a very early age to establish relationships and share information $[54,56,58,59]$. It has been suggested that, even as early as four months of age, infants begin mimicking their mothers' voice patterns in an attempt to communicate $[58,60]$. Communication serves as a means of becoming associated with one another and is a developing process that begins in infancy and becomes more refined throughout childhood.

Researchers interested in studying socialization patterns in children have also started to emphasize the importance of "talk." Barrow [61] suggested that talk as a form of communication helps children better understand the world around them because they can ask questions and ask for clarification. Such talk "offers a window into their thinking" [62, p. 5]. Researchers have even provided suggestions to parents, teachers, and stakeholders to actively teach children to think through problems by "talking them out" in conversation [63]. Other researchers study the inverse instead of investigating communication patterns that children use when guided by adults; they study the way children try to solve problems aloud with no help from an adult to aid with their articulation [64]. Although these studies provide foundational work on the development of communication patterns in children, we are still only beginning to understand the interaction of socialization and communication "talk" patterns and the contribution to organized learning for toddlers and young children [65].

4.1.2. Bioecological Factors Affecting Development. Experiences in the life of a young child lead them to develop more refined communication skills to express to those situated in the systems that exist around them. These experiences occur within the framework of two primary bioecological systems: the home and the child care facility [51, 66-68]. Bioecological systems are defined by Bronfenbrenner [69] as being "the systems that support and guide human growth" (p. 37). These systems consist of meaningful relationships that exist between a child and their school, family, culture, economy, customs, and bodies of knowledge.

Not only are relationships significant in shaping the bioecological system in which a child is situated, but also there are valuable experiences that occur within those systems that contribute to a child's development. For example, home experiences encompass everything that happens to and with a child in the home including the relationships children have with their mothers $[53,57]$. Additionally, the kinds of television programs that children watch [70] contribute to the linguistic development of a child. Even reading has been found to be linked to cultural practices in recent research [55]. Likewise, the experiences that children have in preschool also contribute to their emerging language and cognitive 
competencies [66]. The understanding we have of children's communication and literacy development can be furthered by studying the effects of the bioecological systems of home and child care facilities $[67,68,71,72]$.

Reading to and with young children is one experience within both of these bioecological systems that contributes to literacy development. However, "how we read to children is every bit as important as how often we read to them" [50, p. 31]. Few of those who interact with children know that "a critical factor in shared book reading is the discourse, or verbal interaction, between adults and children" [51, p. 555]. Research has highlighted the importance of adults in the school and home reading and then talking about stories they have read with children [73]. This verbal interaction is the cement that serves as a medium to facilitate vocabulary development. This conversational practice can have an impact not only on a child's understanding of a story but also on the overall communication and literacy development of a child.

4.1.3. Dialogic Reading. One suggested way of promoting communication through dialogue during storybook readings is through the research-supported practice of dialogic reading. Whitehurst and colleagues first introduced dialogic reading in the 1980s [74] as a way to optimize reading time to include concurrent literacy and language development. Recently, dialogic reading has begun to gain interest by researchers in the academy and policy makers $[50,51,75,76]$. One critical factor in dialogic reading is the facilitating of storybook readings by an adult that the child trusts and feels that they can share the reading experience with in a way that allows for their free expression without fear of criticism. Doyle and Bramwell [51] reported that as a result of dialogic readings "children associated readings with social interactions with other children and with their relationship with (their teacher)" and further, "in the context of secure and dependable teacher-student relationships that young children's overall development thrives" (p. 554). This is an interesting observation on the part of those researchers as earlier in this metasynthesis socialization patterns were discussed as a means of facilitating communication development. In this instance it appears as though socialization through storybook reading causes two effects: one is the development of a positive relationship and the next is the child's desire to express understanding of what is read in the story.

Dialogic reading promotes adults to practice repeated storybook readings with kids, starting with an initial reading that allows the child to become acquainted with the text then flowing into a "prompting, evaluating, expanding, and repeating" adult initiated conversation. Dialogic reading such as this is also referred to as the PEER technique [76] for prompting dialogue because "the main goal of dialogic reading is for the child to become the storyteller and the adult to facilitate" [75, p. 118]. After all, "story telling is a powerful context for the development of spoken word" [62, p. 68] and part of the culture that children experience in their everyday life is hearing stories from significant others such as parents, friends, and teachers. Empowering children to become the storyteller allows them to use their unique style to express understanding [77] while encouraging language and literacy development.

It is feasible that practicing this form of storybook reading could also facilitate cross-curricular instruction, particularly in the area of mathematics. A recent study [78] attempted to determine whether or not reading mathematical storybooks using the dialogic reading method created a place for mathematical discourse to occur. In other words, Anderson and colleagues [78] were attempting to determine the effects of reading and mathematics interventions on a child's ability to think and express mathematically. Although a limited number of participants prevented Anderson and colleagues from forming any definitive conclusions regarding the effects of using reading and mathematics interventions on children's early understandings of math concepts, the findings from this study provide a foundational piece for future research into the effects of reading and mathematics interventions that use mathematics storybooks.

Limitations. Although the information found in this metasynthesis does provide a wealth of information regarding the effect that parent and school relationships have on a child's communication development, it is notable that there is a gap in the information provided about what effect reading and mathematics integration can have on a child's ability to think and communicate mathematically. One overwhelming issue that came out of conducting this metasynthesis was that studies on the enhancement of early mathematics development through reading and mathematics interventions have been carried out in international settings $[79,80]$. However, studies conducted internationally were intentionally excluded from this metasynthesis because of the complexities of comparing data from a study carried out outside the US to those done domestically.

It is feasible that there is more information available about the effect that reading and mathematics interventions have on a child's ability to think and communicate mathematically because it is possible that through the process of finding relevant literature by determining "keywords" for inclusion, relevant artifacts could have been excluded. More importantly, although it is plausible that relevant literature was excluded from the current study, it is notable that out of 579 original artifacts, only one actually addressed the effects that reading and mathematics may have on a child's ability to think and communicate mathematically with regard to research conducted with children in the United States. That alone points to a need for further study into the effects of dialogic reading through the lens of creating a foundational mathematics understanding in young children. Still, there is a strong argument to be made for the validity of the findings of this metasynthesis because 22 of the 25 artifacts utilized were from academic journals, three artifacts were books, and one was a conference proceeding. One of the books used in this metasynthesis Handbook of Reading Research, Volume IV [71] is well respected for its breadth of information that it not only has garnered attention by researchers and practitioners but also is referenced by policy makers in order to make more informed decisions regarding reading 
instruction in the classroom. There is value in presenting this spectrum of specific studies within a cohesive vein of thought.

\section{Conclusion}

Research examined through this metasynthesis addressed how and why relationships with significant adults such as parents or caregivers can lead to communication development in young children in order to justify researching the development of a child's ability to think and communicate mathematically. The metasynthesis examined 25 relevant articles from 2000 to 2014 resulting in the identification of two major themes: early childhood communication development and dialogic reading as a means of prompting a child into using dialogue during storybook readings.

Most of the literature reviewed in this metasynthesis addressed research question one: "What factors contribute to a young child's ability to communicate?" The primary theme identified as a means of answering this question was early childhood communication development; two subcategories existed within that theme: sociocognitive development and bioecological environments. According to data presented in the literature, children begin to develop sociocognitively, that is to think and then communicate, in order to express needs, understanding, and association starting at a very young age $[54,56,58-60]$. This attempt on the part of the child to actually communicate with significant "others" in their environment evolves into a more refined method through the development of articulation through speaking, or "talk" $[61-63,65]$. The study of speech patterns in children is significant to this study because it helps identify ways in which a child will want to begin expressing himself or herself, an important consideration to have before delving into a more particular area like facilitating a child's ability to communicate mathematically. It is notable that these researchers all approached a child's communication development through a developmental, educational research lens rather than through a psychological lens. The educational research focus is interesting because educational researchers tend to agree that a child's early development does have an effect on the child's ability to attain skills and excel later in life and yet there is a dearth of educational research on a child's development very early in life.

Another striking finding from this metasynthesis with regard to research question one is the role that significant factors play in a child's early communication development. One factor was the bioecological settings in which a child exists during their ordinary daily life: specifically in the home and preschool [51, 66-69]. Researchers outlined and emphasized how significant the activities that occur within those settings can be to all facets of a child's development $[50,51,53,66-68,70-72]$. Because of the emphasis on the bioecological settings of the home and preschool as critical to a child's early communication development, it is necessary to reiterate that future research studies should focus on these factors not only as unique but also as interdependent to determine the best ways to facilitate early communication development.

With regard to research question two, "What effect does reading and mathematics integration have on a child's ability to think and communicate mathematically?," researchers have only begun to explore the impact that reading and mathematics interventions may have on a child. With regard to thinking and communicating understanding, Doyle and Bramwell [51] reported that using a dialogic approach to reading can help facilitate a child's vocabulary development. Their study provided evidence that when children are encouraged to express understanding of a story while in a "safe" environment with a trusted adult, there is an increase in the child's overall development because the child wants to express understanding and ultimately wants to learn more. More specifically, according to the foundational study done in the US by Anderson and colleagues [78], any child experiencing an integration of reading and mathematics that promotes the use of dialogue in a child should lead to positive outcomes for the child regarding their ability to think and communicate mathematically. However, this study was the only one of its kind identified in this metasynthesis supporting that there is a notable gap for future research to explore the effects of reading and mathematics integration on young children in the US.

It is also important to mention researcher cautions that were found in the literature from this metasynthesis when considering formulating a future study. For example, despite the fact that reading researchers have usually encouraged strict quantitative methodologies in the past, a new push has emerged to encourage flexibility in the field of research [71] to keep open-minded to new methods of studying phenomena. Researchers also encouraged future home studies as a means of gathering data on children [67], citing ecological validity [57] as justification to collect the most authentic data possible from the perspective of a caretaker who is then considered to be a researcher. Some studies cautioned against using video or tape recording when doing studies about young children $[56,58,60,75]$ discussing how those kinds of recording equipment sometimes got in the way of gathering authentic data. These suggestions for further research provide a solid guideline for future studies to follow appropriately to extend the data that are presented here.

The results of this metasynthesis emphasize that further research is needed. Careful consideration must be given to the methods in future studies to maintain the integrity of collected data. By studying family dyads and the effects of this or any phenomena on children in their most safe and secure environment, future research can better understand and explain the ways in which children develop communication skills, particularly when those skills are nurtured through reading and mathematics interventions.

\section{Additional Points}

References were used in the metasynthesis: $[50,51,53-62,64-$ $68,70,71,73,75-78,80]$. 


\section{Competing Interests}

The open access publishing fees for this article were provided by the Texas A\&M University Open Access to Knowledge Fund (OAKFund), supported by the University Libraries and the Office of the Vice President for Research. This fund did not lead to conflict of interests regarding the publication of this paper.

\section{References}

[1] Organisation for Economic Cooperation and Development (OECD), Learning for Tomorrow's World: First Results from PISA 2003, OECD, Paris, France, 2004.

[2] OECD, PISA 2012 Assessment and Analytical Framework: Mathematics, Reading, Science, Problem Solving and Financial Literacy, OECD Publishing, Paris, France, 2013.

[3] J. Sarama, A. A. Lange, D. H. Clements, and C. B. Wolfe, "The impacts of an early mathematics curriculum on oral language and literacy," Early Childhood Research Quarterly, vol. 27, no. 3, pp. 489-502, 2012.

[4] "Reading and mathematics bound together: creating a home environment for preschool learning," Journal of Education and Learning, vol. 5, no. 1, pp. 44-59, 2016.

[5] D. Piccolo, A. Harbaugh, T. Carter, M. M. Capraro, and R. Capraro, "Quality of instruction: examining discourse in middle school mathematics instruction," Journal of Advanced Academics, vol. 19, no. 3, pp. 376-410, 2008.

[6] T. L. Adams, "Reading mathematics: more than words can say," Reading Teacher, vol. 56, no. 8, pp. 786-795, 2003.

[7] R. M. Capraro, M. M. Capraro, and W. H. Rupley, "Readingenhanced word problem solving: a theoretical model," European Journal of Psychology of Education, vol. 27, no. 1, pp. 91-114, 2012.

[8] M. Canale and M. Swain, "Theoretical bases of communicative approaches to second language teaching and testing," Applied Linguistics, vol. 1, no. 1, pp. 1-47, 1980.

[9] C. M. Connor and H. K. Craig, "African American preschoolers' language, emergent literacy skills, and use of African American English: a complex relation," Journal of Speech, Language, and Hearing Research, vol. 49, no. 4, pp. 771-792, 2006.

[10] D. P. Bryant, N. Ugel, S. Thompson, and A. Hamff, "Instructional strategies for content-area reading instruction," Intervention in School and Clinic, vol. 34, no. 5, pp. 293-302, 1999.

[11] M. M. Capraro and H. Joffrion, "Algebraic equations: can middle-school students meaningfully translate from words to mathematical symbols?" Reading Psychology, vol. 27, no. 2-3, pp. 147-164, 2006.

[12] M. Cirillo, K. R. Bruna, and B. Herbel-Eisenmann, "Acquisition of mathematical language: suggestions and activities for english language learners," Multicultural Perspectives, vol. 12, no. 1, pp. 34-41, 2010.

[13] K. D. Muth, "Cognitive demands that arithmetic word problems impose on children," Tech. Rep. ED223422, 1982.

[14] J. De Temple and C. E. Snow, "Learning words from books," in On Reading Books to Children: Parents and Teachers, A. van Kleeck, S. A. Stahl, and E. B. Bauer, Eds., pp. 16-36, Erlbaum, Mahwah, NJ, USA, 2003.

[15] S. Krashen, The Power of Reading: Insights from the Research, Libraries Unlimited, Englewood Cliffs, NJ, USA, 1993.
[16] D. E. Freeman and Y. S. Freeman, Essential Linguistics: What You Need to Know to Teach Reading, ESL, Spelling, Phonics, and Grammar, Heinemann, Portsmouth, NH, USA, 2004.

[17] A. W. Heilman, T. R. Blair, and W. H. Rupley, Principles and Practices of Teaching Reading, Merrill, London, UK, 2002.

[18] A. Debruin-Parecki, "Establishing a family literacy program with a focus on interactive reading: the role of research and accountability," Early Childhood Education Journal, vol. 36, no. 5, pp. 385-392, 2009.

[19] R. Isbell, J. Sobol, L. Lindauer, and A. Lowrance, "The effects of storytelling and story reading on the oral language complexity and story comprehension of young children," Early Childhood Education Journal, vol. 32, no. 3, pp. 157-163, 2004.

[20] A. De Bruin-Parecki, "Assessing adult/child storybook reading practices," Report \#2-004, Center for the Improvement of Early Reading Achievement, 1999.

[21] S. P. Miller and C. D. Mercer, "Educational aspects of mathematics disabilities," Journal of Learning Disabilities, vol. 30, no. 1, pp. 47-56, 1997.

[22] S. P. Miller and C. D. Mercer, "Using data to learn about concrete-semi-concrete-abstract instruction for students with math disabilities," Learning Disabilities Research and Practice,, vol. 8, no. 2, pp. 89-96, 1993.

[23] R. M. Capraro, M. M. Capraro, and W. H. Rupley, "Semantics and syntax: a theoretical model for how students may build mathematical misunderstandings," Journal of Mathematics Education, vol. 3, no. 2, pp. 58-66, 2010.

[24] C. C. Block and J. N. Mangieri, "Recreational reading: 20 years later," The Reading Teacher, vol. 55, no. 6, pp. 572-580, 2002.

[25] A. Wiseman, "Interactive read alouds: teachers and students constructing knowledge and literacy together," Early Childhood Education Journal, vol. 38, no. 6, pp. 431-438, 2011.

[26] L. Bradley and C. Donovan, "Read it! do it! tell it! play it!': preschoolers and their families having fun with stories," Childhood Education, vol. 88, no. 4, pp. 248-254, 2012.

[27] M. H. Buckley, "Oral language: a curriculum yet to come," The English Journal, vol. 84, no. 1, pp. 41-45, 1995.

[28] F. A. Butler and R. Stevens, "Oral language assessment in the classroom," Theory into Practice, vol. 36, no. 4, pp. 214-219, 1997.

[29] L. D. Oczkus, Reciprocal Teaching at Work: Powerful Strategies and Lessons for Improving Reading Comprehension, International Reading Association, Newark, Del, USA, 2nd edition, 2010.

[30] E. M. McTigue, E. K. Washburn, and J. Liew, "Academic resilience and reading: building successful readers," The Reading Teacher, vol. 62, no. 5, pp. 422-432, 2009.

[31] M. S. DeCaro and B. Rittle-Johnson, "Exploring mathematics problems prepares children to learn from instruction," Journal of Experimental Child Psychology, vol. 113, no. 4, pp. 552-568, 2012.

[32] S. H. Landry, K. E. Smith, P. R. Swank, T. Zucker, A. D. Crawford, and E. F. Solari, "The effects of a responsive parenting intervention on parent-child interactions during shared book reading," Developmental Psychology, vol. 48, no. 4, pp. 969-986, 2012.

[33] R. Alexander, Culture and Pedagogy; International Comparisons in Primary Education, Blackwell, Oxford, UK, 2000.

[34] N. Mercer and C. Sams, "Teaching children how to use language to solve maths problems," Language and Education, vol. 20, no. 6, pp. 507-528, 2006. 
[35] E. Graue, M. Clements, A. Reynolds, and M. Niles, "More than teacher directed or child initiated: preschool curriculum type, parent involvement, and children's outcomes in the child-parent centers," Education Policy Analysis Archives, vol. 12, no. 72, pp. 1-36, 2004.

[36] D. Strom, V. Kemeny, R. Lehrer, and E. Forman, "Visualising the emergent structure of children's mathematical argument," Cognitive Science, vol. 25, no. 5, pp. 733-773, 2001.

[37] J. B. Mason and R. Bruning, Providing Feedback in ComputerBased Instruction: What Research Tells Us, Center for Instructional Innovation, University of Nebraska, Lincoln, Neb, USA, 2001.

[38] P. Johnston, "Literacy assessment and the future," Reading Teacher, vol. 58, no. 7, pp. 684-686, 2005.

[39] I. Lundberg, "Early precursors and enabling skills of reading acquisition," Scandinavian Journal of Psychology, vol. 50, no. 6, pp. 611-616, 2009.

[40] T. J. C. Polderman, A. C. Huizink, F. C. Verhulst, C. E. M. van Beijsterveldt, D. I. Boomsma, and M. Bartels, "A genetic study on attention problems and academic skills: results of a longitudinal study in twins," Journal of the Canadian Academy of Child and Adolescent Psychiatry, vol. 20, no. 1, pp. 22-34, 2011.

[41] H. J. Walberg and S.-L. Tsai, "Correlates of reading achievement and attitude: a national assessment study," Journal of Educational Research, vol. 78, no. 3, pp. 159-167, 1985.

[42] M. Westerlund and D. Lagerberg, "Expressive vocabulary in 18month-old children in relation to demographic factors, mother and child characteristics, communication style and shared reading," Child: Care, Health and Development, vol. 34, no. 2, pp. 257-266, 2008.

[43] L. Garrison and J. K. Mora, "Adapting mathematics instruction for English language learners: the language concept connection," in National Council of Teachers of Mathematics. Changing the Faces of Mathematics: Perspectives on Latinos, pp. 35-47, National Council of Teachers of Mathematics, Reston, Va, USA, 1999.

[44] National Association for the Education of Young Children and National Council of Teachers of Mathematics, Early Childhood Mathematics: Promoting Good Beginnings. Joint Position Statement, Joint Position Statement, Washington, DC, USA, 2002.

[45] E. J. Erwin, M. J. Brotherson, and J. A. Summers, "Understanding qualitative metasynthesis: issues and opportunities in early childhood intervention research," Journal of Early Intervention, vol. 33, no. 3, pp. 186-200, 2011.

[46] L. Zimmer, "Qualitative meta-synthesis: a question of dialoguing with texts," Journal of Advanced Nursing, vol. 53, no. 3, pp. 311-318, 2006.

[47] B. L. Paterson, C.-J. Dubouloz, J. Chevrier, B. Ashe, J. King, and M. Moldoveanu, "Conducting qualitative metasynthesis research: insights from a metasynthesis project," International Journal of Qualitative Methods, vol. 8, no. 3, pp. 22-33, 2009.

[48] D. Walsh and S. Downe, "Meta-synthesis method for qualitative research: a literature review," Journal of Advanced Nursing, vol. 50, no. 2, pp. 204-211, 2005.

[49] H. Waxman, Experimental Research, Internal Validity, Quality of Educational Research, vol. 689 of Class meeting of EDCI, Lecture conducted from Texas A\&M University, College Station, Tex, USA, 2010.

[50] R. Arnold, "Charming the next generation: a strategy for turning toddlers into readers," School Library Journal, vol. 51, no. 7, pp. 30-32, 2005.
[51] B. G. Doyle and W. Bramwell, "Promoting emergent literacy and social-emotional learning through dialogic reading," Reading Teacher, vol. 59, no. 6, pp. 554-564, 2006.

[52] J. Jaffe, B. Beebe, S. Feldstein, C. L. Crown, and M. D. Jasnow, "Rhythms of dialogue in infancy: coordinated timing in development," Monographs of the Society for Research in Child Development, vol. 66, no. 2, pp. 1-132, 2001.

[53] J. Brooks-Gunn, W. J. Han, and J. Waldfogel, "First-year maternal employment and child development in the first 7 years," Monographs of the Society for Research in Child Development, vol. 75, no. 2, pp. 1-148, 2010.

[54] A. C. Browne, Teaching and Learning Communication, Language and Literacy, SAGE, London, UK, 2007.

[55] T. Callaghan, H. Moll, H. Rokoczy et al., "Early social cognition in three cultural contexts," Monographs of the Society for Research in Child Development, vol. 76, no. 2, pp. 1-142, 2011.

[56] R. M. Holmes, “'Do you like doritos?': preschoolers' table talk during lunchtime," Early Child Development and Care, vol. 181, no. 3, pp. 413-424, 2011.

[57] A. Palmer and A. J. Baroody, "Blake's development of the number words 'one', 'two', and 'three,' Cognition and Instruction, vol. 29, no. 3, pp. 265-296, 2011.

[58] D. N. Stern, "Face-to-face play: its temporal structure as predictor of socioaffective development," Monographs of the Society for Research in Child Development, vol. 66, no. 2, pp. 144149, 2001.

[59] P. Rochat, "Dialogical nature of cognition," Monographs of the Society for Research in Child Development, vol. 66, no. 2, pp. 133$143,2001$.

[60] C. H. Trautman and P. R. Rollins, "Child-centered behaviors of caregivers with 12-month-old infants: associations with passive joint engagement and later language," Applied Psycholinguistics, vol. 27, no. 3, pp. 447-463, 2006.

[61] W. Barrow, "Dialogic, participation and the potential for Philosophy for Children," Thinking Skills and Creativity, vol. 5, no. 2, pp. 61-69, 2010.

[62] A. Brock and C. Rankin, Communication, Language and Literacy from Birth to Five, Sage, London, UK, 2008.

[63] I. Siraj-Blatchford, K. Sylva, S. Muttock, R. Gilden, and D. Bell, Researching Effective Pedagogy in the Early Years, vol. 356 of Department for Education and Skills Research Report, Department for Education and Skills, London, UK, 2002.

[64] P. D. Zelazo, U. Müller, D. Frye et al., "The development of executive function in early childhood," Monographs of the Society for Research in Child Development, vol. 68, no. 3, 2003.

[65] C. Fernyhough, "Getting Vygotskian about theory of mind: mediation, dialogue, and the development of social understanding," Developmental Review, vol. 28, no. 2, pp. 225-262, 2008.

[66] E. T. Rodriguez and C. S. Tamis-LeMonda, "Trajectories of the home learning environment across the first 5 years: associations with children's vocabulary and literacy skills at prekindergarten," Child Development, vol. 82, no. 4, pp. 1058-1075, 2011.

[67] D. W. Rowe, "The social construction of intentionality: twoyear-olds' and adults' participation at a preschool writing center," Research in the Teaching of English, vol. 42, no. 4, pp. 387-434, 2008.

[68] D. J. Weigel, S. S. Martin, and K. K. Bennett, "Ecological influences of the home and the child-care center on preschool-age children's literacy development," Reading Research Quarterly, vol. 40, no. 2, pp. 204-233, 2005. 
[69] U. Bronfenbrenner, "Ecological models of human development," in International Encyclopedia of Education, vol. 3, pp. 37-43, Elsevier, Oxford, UK, 2nd edition, 1994, Reprinted in: Gauvain, M. \& Cole, M. Ed., Readings on the Development of Children, Freeman, 2nd Ed, New York, NY, USA, 1993.

[70] A. M. Moses, "What television can (and can't) do to promote early literacy development," YC Young Children, vol. 64, no. 2, pp. 80-89, 2009.

[71] M. Kamil, E. Moje, P. Pearson, and P. Afflerbach, Handbook of Reading Research, vol. 4, Routledge, New York, NY, USA, 2010.

[72] P. D. Pearson, R. Barr, M. L. Kamil, and P. Mosenthal, Handbook of Reading Research, Longman, New York, NY, USA, 1984.

[73] P. L. Steinhaus, "Nurturing phonemic awareness and alphabetic knowledge in pre-kindergarteners," in Proceedings of the Lilian Katz Symposium, Champaign, Ill, USA, November 2000.

[74] G. J. Whitehurst, F. L. Falco, C. J. Lonigan et al., "Accelerating language development through picture book reading," Developmental Psychology, vol. 24, no. 4, pp. 552-559, 1988.

[75] J. Blom-Hoffman, T. O’Neil-Pirozzi, J. Cutting, and E. Bissinger, "Instructing parents to use dialogic reading strategies with preschool children: impact of a video-based training program on caregiver reading behaviors and children's related verbalizations," Journal of Applied School Psychology, vol. 23, no. 1, pp. 117-131, 2006.

[76] US Department of Education, Institute of Education Sciences, National Center for Education Evaluation, Regional Assistance, and What Works Clearinghouse, Early Childhood Education: Dialogic Reading, National Center for Educational Evaluation and Regional Assistance, Institute of Education Sciences, U.S. Dept. of Education, Washington, DC, USA, 2010.

[77] E. Hughes, "Planning meaningful curriculum a mini story of children and teachers learning together," Childhood Education, vol. 78, no. 3, pp. 134-139, 2002.

[78] A. Anderson, J. Anderson, and J. Shapiro, "Mathematical discourse in shared storybook reading," Journal for Research in Mathematics Education, vol. 35, no. 1, pp. 5-33, 2004.

[79] A. Anderson, J. Anderson, and J. Shapiro, "Supporting multiple literacies: parents' and children's mathematical talk within storybook reading," Mathematics Education Research Journal, vol. 16, no. 3, pp. 5-26, 2005.

[80] S. E. Mol, A. G. Bus, M. T. De Jong, and D. J. H. Smeets, "Added value of dialogic parent-child book readings: a meta-analysis," Early Education and Development, vol. 19, no. 1, pp. 7-26, 2008. 


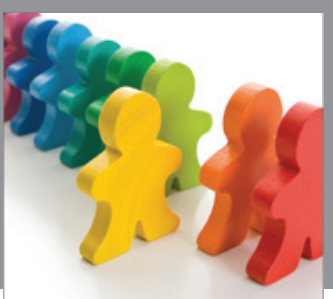

Autism

Research and Treatment
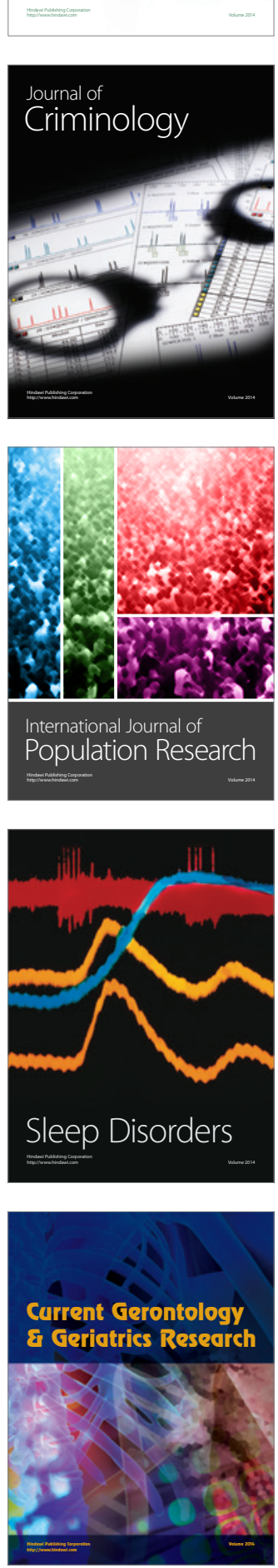

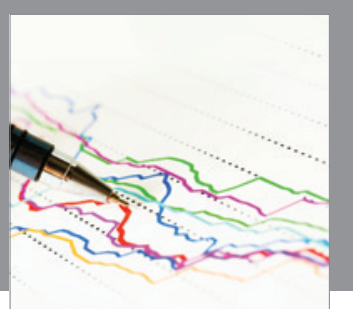

Economics

Research International
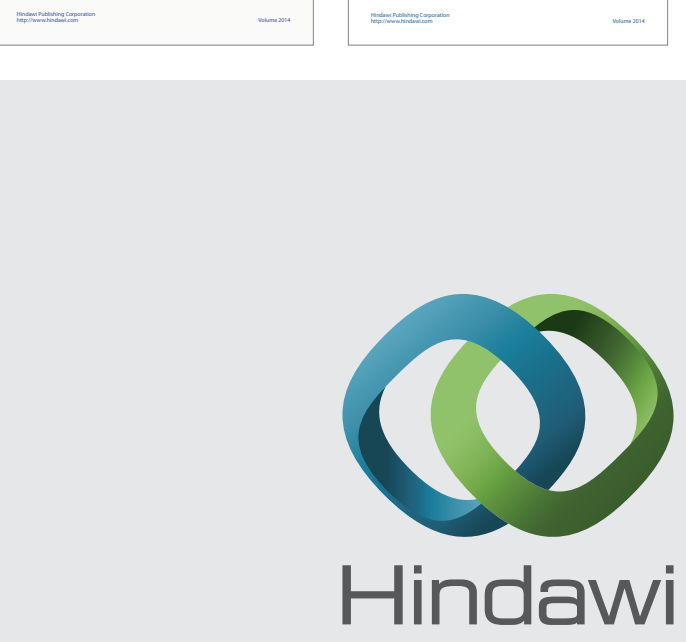

Submit your manuscripts at

https://www.hindawi.com
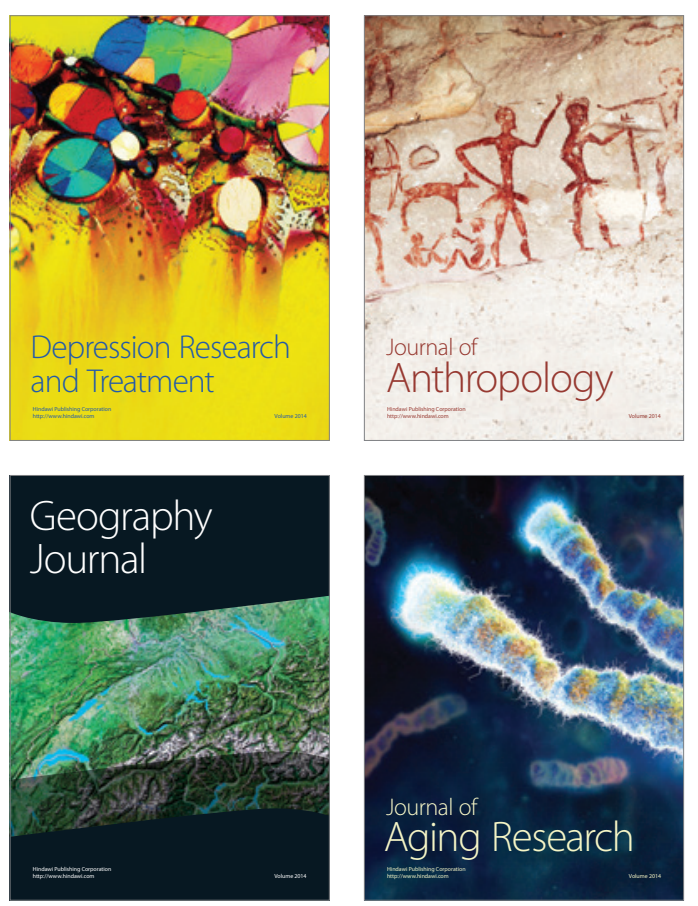
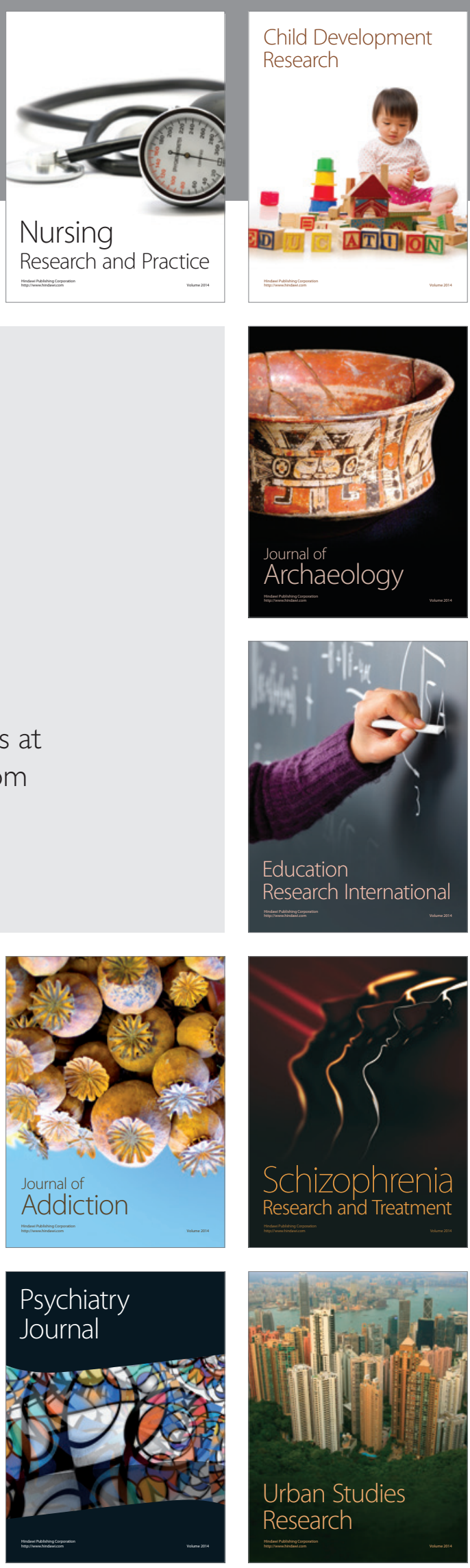